\title{
Correction to: Real-World Evidence of the Clinical and Economic Impact of Long-Acting Injectable Versus Oral Antipsychotics Among Patients with Schizophrenia in the United States: A Systematic Review and Meta-Analysis
}

\author{
Dee Lin ${ }^{1} \cdot$ Philippe Thompson-Leduc ${ }^{2} \cdot$ Isabelle Ghelerter ${ }^{2} \cdot \mathrm{Ha} \mathrm{Nguyen}^{3} \cdot$ Marie-Hélène Lafeuille $^{2}$. \\ Carmela Benson $^{1}$ - Panagiotis Mavros ${ }^{1} \cdot$ Patrick Lefebvre $^{2}$
}

Published online: 4 August 2021

(c) Springer Nature Switzerland AG 2021

\section{Correction to: CNS Drugs (2021) 35(5):469-481 https://doi.org/10.1007/s40263-021-00815-y}

The article 'Real-World Evidence of the Clinical and Economic Impact of Long-Acting Injectable Versus Oral Antipsychotics Among Patients with Schizophrenia in the United States: A Systematic Review and Meta-Analysis' by Dee Lin, Philippe Thompson-Leduc, Isabelle Ghelerter, Ha Nguyen, Marie-Hélène Lafeuille, Carmela Benson, Panagiotis Mavros and Patrick Lefebvre, was originally published electronically on SpringerLink on 28 April 2021.
After publication in volume 35, issue 5, pages 469-481, the authors highlighted that two of the references cited in the Supplementary Information were incorrect. This error has been rectified and a new corrected version of the Supplementary Information has been uploaded with the manuscript on SpringerLink.

The original article has been corrected.

Supplementary Information The online version contains supplementary material available at https://doi.org/10.1007/s40263-021-00850-9.
The original article can be found online at https://doi.org/10.1007/ s40263-021-00815-y.

Philippe Thompson-Leduc

Philippe.Thompson-Leduc@analysisgroup.com

Janssen Scientific Affairs, LLC, Titusville, NJ, USA

2 Analysis Group, Inc., Montreal, QC, Canada

3 Analysis Group, Inc, Boston, MA, USA 